\title{
Salt-Assisted SHS Synthesis of Aluminium Nitride Powders for Refractory Applications
}

\author{
Alan Wilmański, Mirosław M. Bućko, Zbigniew Pędzich, Jacek Szczerba \\ AGH University of Science and Technology, Faculty of Materials Science and Ceramics, Krakow, Poland \\ Email: bucko@agh.edu.pl
}

Received July 2014

\begin{abstract}
Powders of aluminum nitride can be prepared by self-sustain high-temperature synthesis (SHS) between aluminum and nitrogen but its high exothermic effect causes melting and evaporation of aluminum and low efficiency of such reaction. A presence of inorganic salt in the starting powder mixture can decrease a heat evolved in the SHS reaction, hinders melting and coalescence of aluminum, and facilitates penetration of nitrogen into interior of a powder bed. Mixtures of alumina powders with different grain sizes and different amounts of aluminum carbonate were subjected to the SHS reaction under $0.05,0.1$ or $1 \mathrm{MPa}$ nitrogen. The powders were composed of aluminum nitride, unreacted aluminum, aluminum oxynitride and in some cases corundum and aluminum oxycarbonate. The finale effects are strongly dependent on the amount of the salt, a grain size of aluminum and a nitrogen pressure.
\end{abstract}

\section{Keywords}

Aluminum Nitride, Self-Sustain High-Temperature Synthesis, Salt Assisted Synthesis, Refractory Materials

\section{Introduction}

Aluminum nitride, AlN, is a promising ceramic material for functional and structural applications due to its very high thermal conductivity, low electrical conductivity, high flexural strength of about $400 \mathrm{MPa}$ and a hardness of about 15 GPa [1]-[3]. Several arguments speak for use sintered polycrystalline AlN materials also as a refractory materials: high thermal stability, good thermal shock resistance, and resistance to molten alkali salts [4]. Aluminium nitride was used as a refractory materials alone [5] [6] or as an ingredient of multicomponent materials based on aluminum oxide [7] or aluminum oxynitride [8]. Presence of aluminum nitride in a mixture with aluminum oxynitride or corundum powders allow for their compaction using the hydrolysis reaction of AlN [9].

There are several methods for preparing aluminum nitride powders. The commonly used method is direct reaction between aluminum powder and nitrogen or ammonia at elevated temperature for several hours [10]. Carbothermal reduction of aluminum oxide at the same atmospheres at $1800^{\circ} \mathrm{C}$ can be also used but a product powders are highly aggregated and contaminated with carbon and aluminum carbide [11]. Aluminum nitride powders can also be prepared in an electric arc, however, apparatus, control conditions and energy consumption are considerable obstacle [12]. 
A relatively simple and quick method of aluminum nitride preparation is self-sustain high-temperature synthesis (SHS) [13]. In such a case, reaction between aluminum powder, usually in a form of porous and loos bed, and nitrogen is initiated. Very high heat of such reaction causes increase of temperature enough to its sustain but also to melt and partially evaporate of aluminum. These phenomena are the reasons of relatively low efficiency of the synthesis process. Usually two ways are used to avoid such drawback - decrease of a nitrogen partial pressure and dilution of the aluminum bed with aluminum nitride powder.

There are several papers described SHS synthesis of aluminum nitride powders where a small amount of inorganic substances are added. One of the used additives was ammonium chloride and it was stated that optimum amount of the salt depended on the aluminum grain size, the bigger aluminum grains the highest salt content [14]. Similar effects were observed when a small amount, from 0.5 to 1.5 mass\%, of ammonium fluoride were added into a mixture of aluminum and aluminum nitride powders [15]. For both salt used efficiency of SHS synthesis of aluminum nitride increased.

The described influence of inorganic salts on SHS synthesis of AlN is usually attributed to their reaction with surface of aluminum grains. Thermal decomposition of ammonium chloride or fluoride lead to formation of very reactive atomic nitrogen as well as chloride or fluoride anions that react with an aluminum oxide presented on a surface of metallic grains facilitate its removing. In our opinion, presence of a higher amount of inorganic salt in the starting powder mixture can also decreases a heat evolved in the SHS reaction, hinders melting and coalescence of aluminum, and facilitates penetration of nitrogen into interior of the bed.

The aim of the present work was determination of ammonium carbonate on SHS synthesis of aluminum nitride powders while aluminum powders with different grain sizes and different pressures of nitrogen were applied.

\section{Experiment}

Two kind of commercial aluminum powder (Benda-Lutz) were used in the preparation. The first one, marked as Al-7, was composed of rounded but irregular grains with average size of ab. $8 \mu \mathrm{m}$. The second powder with irregular and not so rounded grains of about $50 \mu \mathrm{m}$ was marked as Al-63. Figure 1 shows grain size distributions of the applied alumina powders.

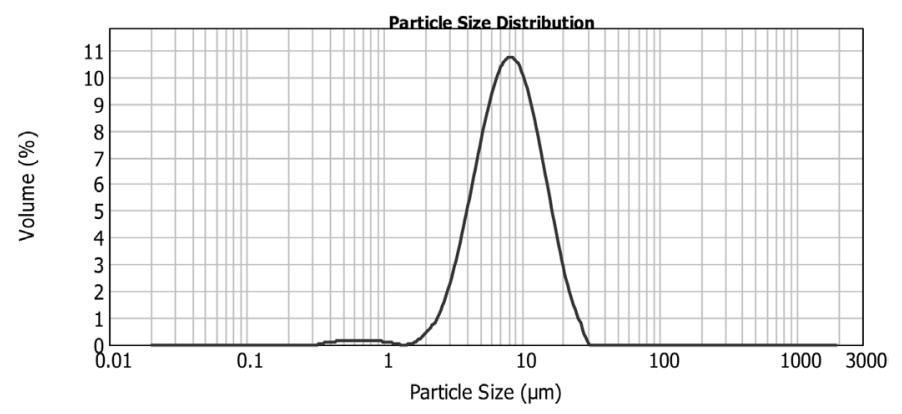

(a)

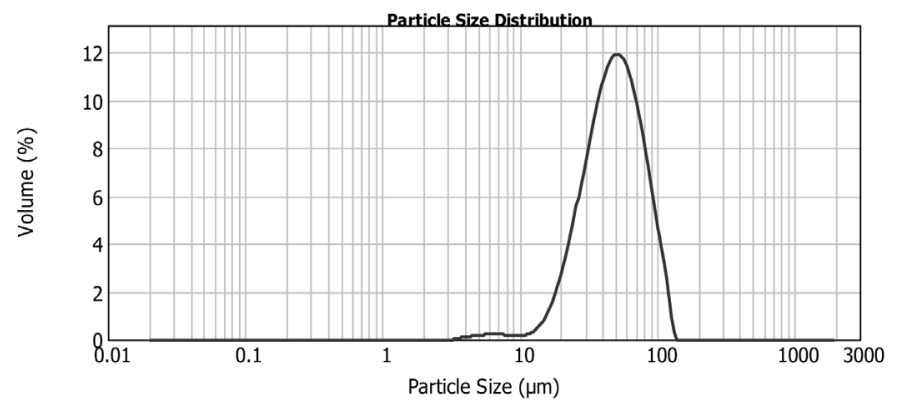

(b)

Figure 1. Grain size distributions of the applied aluminum powders. (a) Al-7 powder; (b) Al-63 powder. 
The alumina powders were carefully mixed in a plastic container with ammonium carbonate for 30 min using a few zirconia grinding balls and small amount of dry isopropanol. The volume fractions of the salt were established at $10 \%, 20 \%, 30 \%$ and $40 \%$. The powder mixtures were dried at the room temperature and placed in a form of loos, porous bed into container made of graphite foil. The container was thermally isolated with corundum wool and placed into a pressure chamber. The chamber was vacuumed and filled with nitrogen to $0.05,0.1$ or $1 \mathrm{MPa}$. The reaction was initialized by an electric current flow through the graphite container.

Phase composition of the powders was determined by X-ray diffraction analysis (X'Pert Pro, Panalytical) and the Rietveld refinement was used to determine quantitative phase content. Morphology of the powders was observed using scanning electron microscopy (Nova NanoSEM 200, FEI).

\section{Results and Disscusion}

X-ray diffraction analysis reveals that all SHS-derived powders are composed mostly of aluminum nitride and remains of non-reacted aluminum. In the powders prepared from the mixtures with larger content of the salt a small amounts of aluminum oxynitride with the spinel structure, $\gamma$-alon, corundum and aluminum oxycarbide, $\mathrm{Al}_{2} \mathrm{OC}$, are also present. Figure 2 shows changes of aluminum nitride content in the SHS-derived powders.

In the case of pure aluminum powder, amount of aluminum nitride in the SHS-derived powder did not exceed 45 mas\%. The highest amount of AlN was observed in the powder synthesized from the Al-7 powder at 0.05 MPa but increase of the nitrogen pressure did not lead to the monotonic decrease of AlN content. The 10 mas\% addition of the salt led to a significant increase in efficiency of the AlN synthesis reaction except the Al-63 powder reacted under $0.05 \mathrm{MPa}$.

When the Al-7 powder was used, regardless of the nitrogen pressure, the SHS-derived powders contained over 80 mass\% of aluminum nitride. The effect associated with a further increase of the amount of the salt was little varied depending on the nitrogen pressure. For the highest nitrogen pressure, $1 \mathrm{MPa}$, the increase of ammonium carbonate content in the starting powder mixture led to a small decrease of the amount of AlN in the powder after SHS reaction. For the other pressures a small increase and then also small decrease of AlN content can be observed. The smallest amount of AIN contained the powders reacted under the lowest nitrogen pressure.
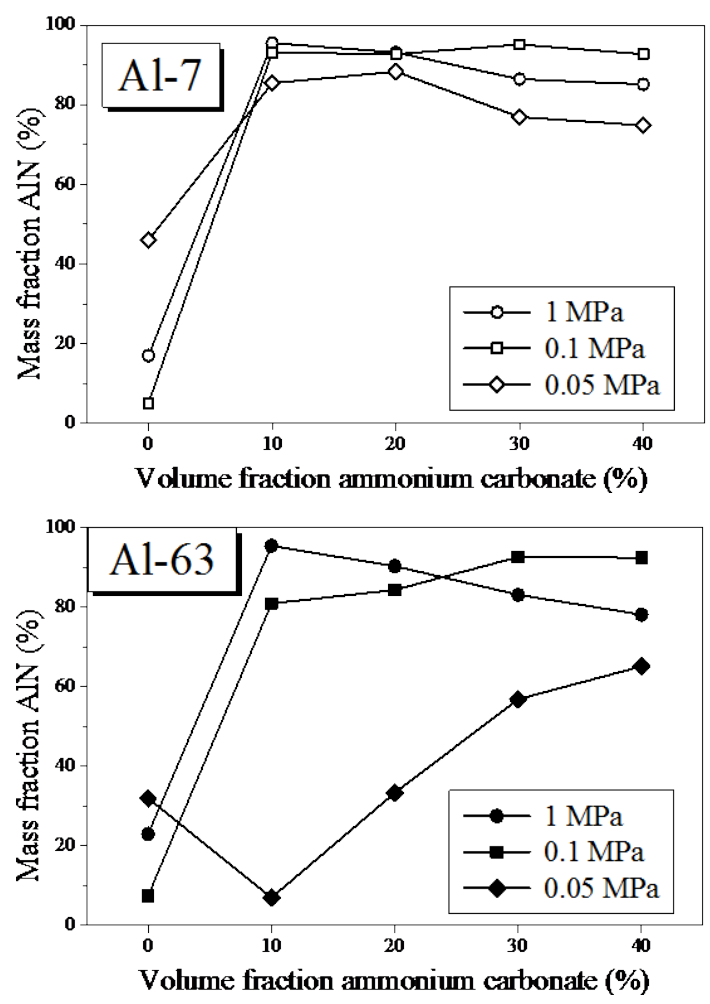

Figure 2. Aluminum nitride content in the SHS-derived powders in relation to the ammonium carbonate content. 
The nature of the presented relations shows that the aluminum grain size also influences efficiency of the synthesis reaction. In the powders prepared from the alumina powder with the larger grains, Al-63, presence of the salt lead to an increase of the AlN content when the nitrogen pressure is higher than $0.05 \mathrm{MPa}$. In this case a decrease of AlN content was observed. Further increase of ammonium carbonate caused increase of the AlN content when the nitrogen pressure is low and decrease for the higher one.

Unreacted aluminum, aluminum oxynitride with spinel structure, $\gamma$-alon, corundum and aluminum oxycarbide, $\mathrm{Al}_{2} \mathrm{OC}$, were balance phases in the SHS-derived powders when the Al-7 powder was used. Figure 3 shows changes of the oxide phase contents in relation to the amount of the salt in the starting mixtures. Presence of aluminum oxide in the SHS-derived powders results of a reaction between aluminum and oxygen, or carbon oxides resulting from ammonium carbonate decomposition. Based on the previous work it can be assumed that the aluminum oxynitride is formed in a secondary reaction between aluminum nitride and aluminum oxide [16]:

$$
\mathrm{AlN}+\mathrm{Al}_{2} \mathrm{O}_{3} \rightarrow \mathrm{Al}_{3} \mathrm{O}_{3} \mathrm{~N}
$$

This reaction is endothermic and high temperature is required to its occurrence, therefore it can be assumed that a higher specific surface of the Al-7 powder leads to more intensive course highly exothermic reaction between aluminum and nitrogen, and consequently to a higher adiabatic temperature. An increase of the ammonium carbonate content and dilution of the aluminum powder causes a decrease of the temperature but also a higher amount of oxygen in the system intensifies synthesis of $\gamma$-alon. Presence of corundum in the SHS-derived powders prepared under $0.05 \mathrm{MPa}$ with 30 and $40 \mathrm{vol} \%$ of the salt corroborates this statement. For the same nitrogen pressure and the salt content a partial pressure of carbon oxides was as high as enough to form aluminum oxycarbide:

$$
2 \mathrm{Al}+\mathrm{CO} \rightarrow \mathrm{Al}_{2} \mathrm{OC}
$$

SEM observations reveal that morphology of the SHS-derived powders is complex and very diversified. Figure 4 shows some SEM pictures of the powders prepared from different aluminum powders, under different nitrogen pressure, and with different amounts of the salt. The first pictures present a morphology of the powders
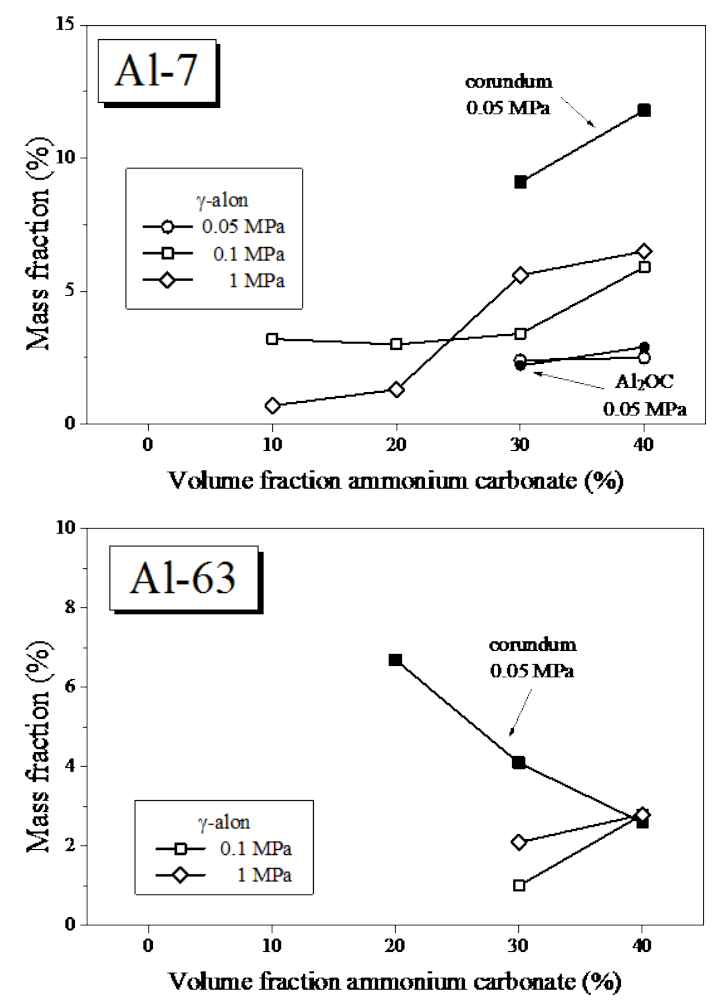

Figure 3. Oxide phases content in the SHS-derived powders in relation to the ammonium carbonate content. 


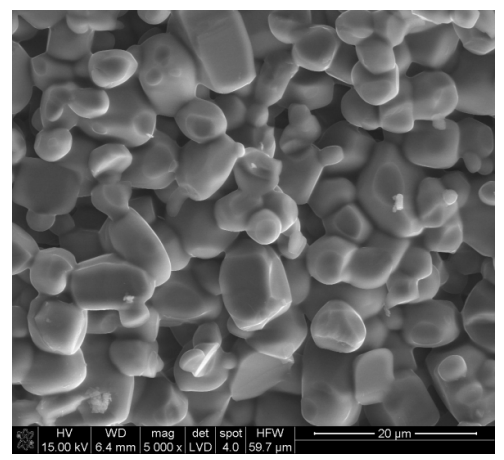

(a)

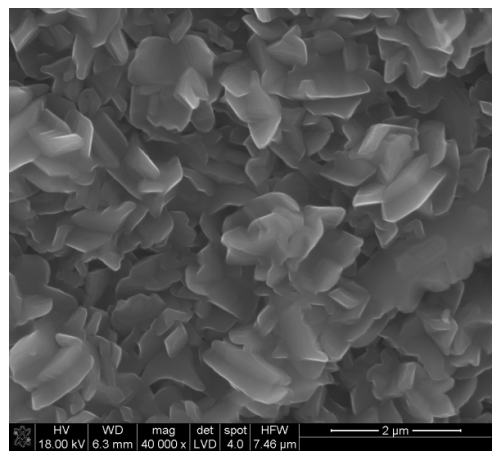

(d)

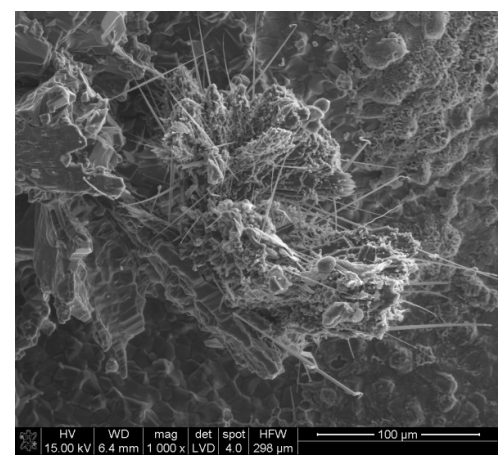

(b)

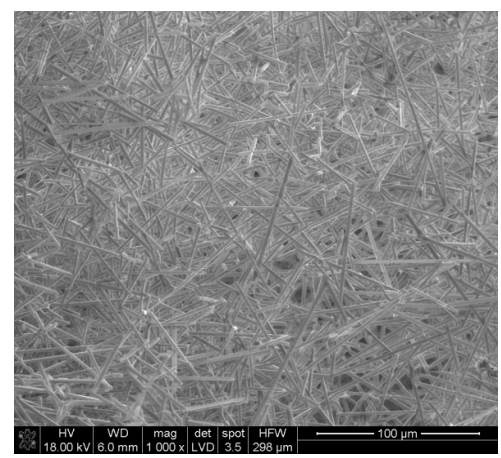

(e)

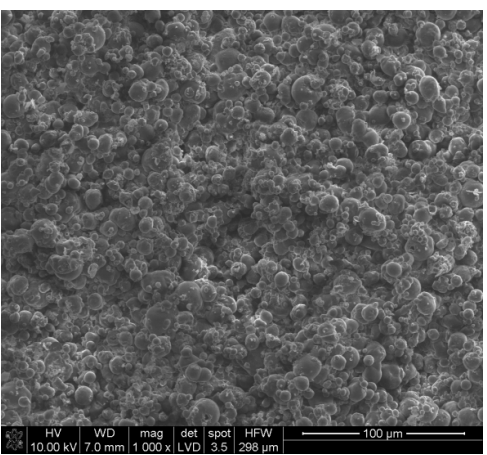

(c)

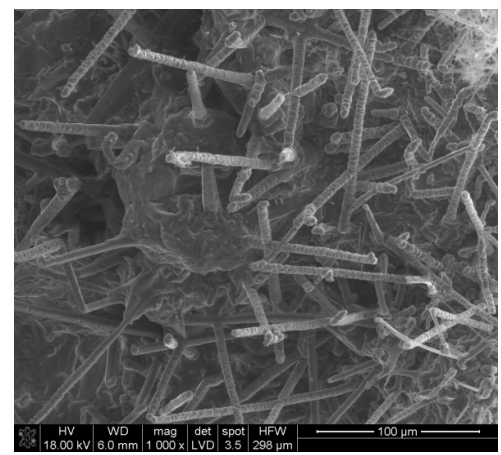

(f)

Figure 4. SEM images of the SHS-derived powders. (a) Al-7, $1 \mathrm{MPa}$; (b) Al-63, $0.1 \mathrm{MPa}$; (c) Al-7, 10\% salt, $1 \mathrm{MPa}$; (d) Al-63, 10\% salt, $0.1 \mathrm{MPa}$; (e) Al-7, 30\% salt, $0.05 \mathrm{MPa}$; (f) Al-63, 30\% salt, $0.1 \mathrm{MPa}$.

prepared without a presence of the salt. Most of the aluminum nitride grains, all phases were detected by EDS method, have a regular isometric shapes and sizes from 5 to $10 \mu \mathrm{m}$. Plate-like or elongate AlN grains, suggesting the VLS (vapor-liquid-solid) or the VS (vapor-solid) mechanism of their formation, indicate a presence of the gas and/or liquid aluminum during the SHS reaction.

Similar diversity of morphology can be observed in the powders synthesized by SHS method with the addition of ammonium carbonate. Most of the aluminum nitride particles have regular shapes and sizes up to $10 \mu \mathrm{m}$. High temperature of the synthesis makes these grains form aggregates and agglomerates larger than hundreds of microns. Plate-like and/or elongated AlN grains are visible indicating a presence of liquid and gaseous aluminum. Among elongated crystals of AlN can be recognized both whiskers and forms of larger diameter composed of a single, hexagonal plates of nanometer sizes. It is possible to find some areas showing a sequential proceed of reactions. SEM picture of the powder prepared under $0.1 \mathrm{MPa}$ from the mixture of the Al-63 powder and 30 vol\% salt reveals aggregate composed of aluminum nitride grains coated of short needle-like crystals of the same phase. In the case of the powders synthesized in a presence of larger amounts of the salt very large and poreless aggregates can be observed. On their surfaces individual, smaller particles of AlN are placed probably due to the secondary reaction of liquid aluminum with nitrogen.

\section{Summary}

Aluminum nitride can be prepared by direct reaction between aluminum and nitrogen although a high heat of this reaction required a relatively low nitrogen pressure and/or dilution of aluminum powder with AlN. The presented results clearly show that a presence of ammonium carbonate in the starting powder mixture for the SHS synthesis significantly improves efficiency of this reaction. The effects are strongly dependent on the amount of introduced salt, aluminum powder morphology and a nitrogen pressure. In the case of the bigger aluminum grains the higher nitrogen pressure the higher optimal amount of ammonium carbonate, which gives over 90 mass\% aluminum nitride in the final powder. Prepared powders were characterized by a complex morphology; besides isometric AlN grains plate-like and elongated particles can be also visible, which indicates a presence of gaseous and/or liquid phases during the reaction. 


\section{Acknowledgements}

The work was financially supported by the Polish State National Centre for Research and Development under Program INNOTECH-K2/IN2/16/181920/NCBR/13.

\section{References}

[1] Pierson, H.O. (1996) Handbook of Refractory Carbides and Nitrides, Properties, Characteristics, Processing and Applications. Elsevier Science.

[2] Wang, P.L., Sun, W.Y. and Yan, D.S. (1999) Mechanical Properties of AlN-Polytypoids-15R, 12H and 21R. Materials Science and Engineering: A, 272, 351-356. http://dx.doi.org/10.1016/S0921-5093(99)00500-6

[3] Slack, G.A. (1973) Nonmetallic Crystals with High Thermal Conductivity. Journal of Physics and Chemistry of Solids, 34, 321-335. http://dx.doi.org/10.1016/0022-3697(73)90092-9

[4] Sato, T., Kanno, Y. and Shimada, M. (1986) Corrosion of SiC, $\mathrm{Si}_{3} \mathrm{~N}_{4}$ and AlN in Molten $\mathrm{K}_{2} \mathrm{SO}_{4}-\mathrm{K}_{2} \mathrm{CO}_{3}$ Salts. International Journal of High Technology Ceramics, 2, 279-290. http://dx.doi.org/10.1016/0267-3762(86)90021-4

[5] Kartavykh, A.V., Tcherdyntsev, V.V. and Zollinger, J. (2009) TiAl-Nb Melt Interaction with AlN Refractory Crucibles”, Materials Chemistry and Physics, 116, 300-304. http://dx.doi.org/10.1016/j.matchemphys.2009.03.032

[6] Himpel, G., Herrmann, M., Höhn, S. and Klinger, M. (2014) High-Temperature Corrosion of Aluminium Nitride Ceramics by Coal Ashes. Journal of the European Ceramic Society, 34, 267-276. http://dx.doi.org/10.1016/j.jeurceramsoc.2013.08.030

[7] Yoshimura, H.N., Abreu, A.P., Molisani, A.L., de Camargo, A.C., Portela, J.C.S. and Narita, N.E. (2008) Evaluation of Aluminum Dross Waste as Raw Material for Refractories. Ceramics International, 34, 581-591. http://dx.doi.org/10.1016/j.ceramint.2006.12.007

[8] Pichlbauer, S., Harmuth, H., Lencés, Z. and Sajgalík, P. (2012) Preliminary Investigations of the Production of MgAION Bonded Refractories. Journal of the European Ceramic Society, 32, 2013-2018. http://dx.doi.org/10.1016/j.jeurceramsoc.2011.10.036

[9] Bućko, M.M., Domagała, J. and Lach, R. (2014) Consolidation of Aluminium Oxynitride Powders Using Hydrolysis of Aluminium Nitride. Key Engineering Materials, 602-603, 170-174. http://dx.doi.org/10.4028/www.scientific.net/KEM.602-603.170

[10] Haussonne, J.M., Lostec, J. and Bertot, J.P. (1993) A New Synthesis Process for AlN. American Ceramic Society Bulletin, 72, 84-90.

[11] Cho, Y.W. and Charles, J.A. (1991) Synthesis of Nitrogen Ceramic Powders by Carbothermal Reduction and Nitridation. III: Aluminium Nitride. Materials Science and Technology, 7, 495-504. http://dx.doi.org/10.1179/mst.1991.7.6.495

[12] Li, H.D., Zou, G.T., Wang, H., Yang, H.B., Li, D.H. and Li, M.H. (1998) Synthesis and Infrared Study of Nanosized Aluminum Nitride Powders Prepared by Direct Current Arc Plasma. Journal of Physical Chemistry B, 102, 8692-8695. http://dx.doi.org/10.1021/jp981486x

[13] Subrahmanyan, J. and Visayakumar, M. (1992) Review: Self-Propagating High-Temperature Synthesis. Journal of Materials Science, 27, 6249-6273.

[14] Rosenband, V. and Gany, A. (2004) Activation of Combustion Synthesis of Aluminum Nitride Powder. Journal of Materials Processing Technology, 147, 197-203. http://dx.doi.org/10.1016/j.jmatprotec.2003.12.017

[15] Sakurai, T., Yamada, O. and Miyamoto, Y. (2006) Combustion Synthesis of Fine AlN Powder and its Reaction Control. Materials Science and Engineering A, 416, 40-44. http://dx.doi.org/10.1016/j.msea.2005.09.111

[16] Zientara, D., Bućko, M.M. and Lis, J. (2007) Alon-Based Materials Prepared by SHS Technique. Journal of the European Ceramic Society, 27, 775-779. http://dx.doi.org/10.1016/j.jeurceramsoc.2006.04.008 